\title{
3 \\ A HUMANIZAÇÃO NA SAÚdE NO CURSO TÉCNICO EM ENFERMAGEM DA ESCOLA TÉCNICA DE SAÚDE DA UFU*1
}

\author{
Lilian Rodrigues Sant' Anna Campos \\ Selva Guimarães
}

\section{Introdução}

A Constituição da República Federativa do Brasil de 1988, estabeleceu a saúde como direito de todos e dever do Estado, a quem compete garanti-la mediante políticas sociais e econômicas. $\mathrm{O}$ acesso à saúde deve ser universal e igualitário. A assistência integral e as ações e serviços de saúde passam a se integrar em uma rede, formando o Sistema Único de Saúde (SUS) (BRASIL, 1988). A pandemia da COVID-19 que afetou o mundo e o Brasil, de forma avassaladora, expôs a força, a importância e, ao mesmo tempo, as fragilidades do SUS no cenário complexo e profundamente desigual do nosso país.

O sistema de saúde nacional foi regulamentado pela Lei n. ${ }^{\circ}$ 8.080, de 1990 (BRASIL, 1990).

O SUS representa a materialização de uma nova concepção acerca da saúde em nosso país. Antes a saúde era entendida como "o Estado de não doença", o que fazia com que toda lógica girasse em torno da cura de agravos à saúde. Essa lógica, que significava apenas remediar os efeitos com menor ênfase nas causas, deu lugar a uma nova noção centrada na prevenção dos agravos e na promoção da saúde. Para tanto, a saúde passa a ser relacionada com a qualidade de vida da população (BRASIL, 2000, p. 5).

O SUS estabeleceu princípios para a promoção, prevenção e reabilitação da saúde de forma mais justa e humanizada (BRASIL, 1990). Porém, mesmo com as diversas ações realizadas para a promoção de uma assistência à saúde com qualidade, persistem problemas nesse sistema.

Segundo Oliveira, Collet e Viera (2006, p. 278),

[...] o SUS instituiu uma política pública de saúde que, apesar dos avanços acumulados, hoje, ainda enfrenta fragmentação do processo de trabalho e das relações entre os diferentes profissionais, fragmentação da

${ }^{*}$ DOI - 10.29388/978-65-86678-49-9-0-f.55-70

1 Este texto é produto da Dissertação: A humanização na saúde no Curso Técnico em Enfermagem da Escola Técnica de Saúde da UFU. 
rede assistencial, precária interação nas equipes, burocratização e verticalização do sistema, baixo investimento na qualificação dos trabalhadores, formação dos profissionais de saúde distante do debate e da formulação da política pública de saúde, entre outros aspectos [...], resultantes de ações consideradas desumanizadas na relação com os usuários do serviço público de saúde.

Para atenuar essas dificuldades e aperfeiçoar o SUS, o Ministério da Saúde criou em 2003, a Política Nacional de Humanização (PNH)- Humaniza SUS, documento de referência sobre as práticas de humanização na saúde. A PNH concebe a humanização "[...] como um conjunto de estratégias para alcançar a qualificação da atenção e da gestão em saúde no SUS" (BRASIL, 2004, p. 8). Tem como meta "[...] transformar as relações de trabalho a partir da ampliação do grau de contato e da comunicação entre as pessoas e grupos, retirando-os do isolamento e das relações de poder hierarquizadas" (BRASIL, 2015).

De acordo com Pasche e Passos (2008, p. 95),

[...] a PNH aposta no reposicionamento dos sujeitos, ou seja, no seu protagonismo, na potência do coletivo, na importância da construção de redes de cuidados compartilhados: uma aposta política. Destaca os "direitos das pessoas" usuários e trabalhadores de saúde, com a potencialização da capacidade de criação que constitui o humano, valorizando sua autonomia em uma configuração coletiva dos processos de atenção e gestão.

A política de humanização na saúde reconhece as vozes dos indivíduos que usufruem e fazem parte do SUS. A PNH propõe a valorização dos profissionais da saúde e condições para que se possa prestar uma assistência de qualidade, fortalecendo os serviços de saúde.

Os profissionais da enfermagem são responsáveis pelos cuidados e procedimentos necessários para o restabelecimento da saúde das pessoas. De acordo com a Resolução COFEN n. ${ }^{\circ} 564 / 2017$, “[...] a Enfermagem é comprometida com a produção e gestão do cuidado prestado nos diferentes contextos socioambientais e culturais em resposta às necessidades da pessoa, família e coletividade". O profissional de Enfermagem deve atuar com autonomia e em consonância com os preceitos éticos e legais, técnico-científico e teórico-filosófico; exercer suas atividades com competência para promoção do ser humano na sua integralidade, de acordo com os "Princípios da Ética e da Bioética" (COFEN, 2017).

Conforme pesquisa do Conselho Federal de Enfermagem (COFEN), no ano de 2019 havia no país 2.216.184 profissionais de enfermagem inscritos 
nos órgãos de fiscalização regionais, os Conselhos Regionais de Enfermagem (COREN). Desse total, $1.261 .365(56,91 \%)$ são técnicos de enfermagem, $537.898(24,27 \%)$ enfermeiros, $416.652(18,8 \%)$ auxiliares e 269 obstetrizes (0.01\%) (COFEN, 2019).

De acordo com a Lei n. ${ }^{\mathbf{0}} 7.498 / 1986$,

Art. 12. O Técnico de Enfermagem exerce atividade de nível médio, envolvendo orientação e acompanhamento do trabalho de enfermagem em grau auxiliar, e participação no planejamento da assistência de enfermagem, cabendo-lhe especialmente: participar da programação da assistência de enfermagem; executar ações assistenciais de enfermagem, exceto as privativas do Enfermeiro [...]; participar da orientação e supervisão do trabalho de enfermagem em grau auxiliar; participar da equipe de saúde (SANTOS et al, 1997, p. 46).

Os profissionais técnicos constituem a maior parte da categoria; desempenha cuidados ao paciente; fazem um intermédio na equipe de enfermagem. Assim, os técnicos em enfermagem são essenciais para o fortalecimento do sistema de saúde. Suas ações impactam o local de trabalho, propiciando um ambiente humanizado ou desumanizado.

Nessa perspectiva, defendemos a necessidade de implementar a política de humanização nos serviços de saúde e investir na formação dos profissionais de enfermagem. Faz-se necessário construir uma cultura de humanização para a melhoria das condições de atendimento em saúde, uma formação que explore o potencial dos profissionais, para enfrentar dificuldades e propor soluções.

Consideramos imperativa a realização de pesquisas acerca da formação, das conquistas e das dificuldades dos técnicos de enfermagem no Brasil, uma vez que constituem o maior contingente de enfermagem e possuem papel relevante na promoção da saúde. Dessa forma, refletimos sobre a humanização na saúde promovida pelo Curso Técnico em Enfermagem da Escola Técnica de Saúde (ESTES) da Universidade Federal de Uberlândia (UFU). Questionamos: A humanização tem sido abordada e vivenciada no Curso? $\mathrm{O}$ que pensam os docentes e os egressos sobre esse tema? Como o é abordado no Projeto Político Pedagógico (PPP) do Curso?

A humanização na saúde evidenciada na formação do aluno favorece o incentivo ao aperfeiçoamento das relações interpessoais, a valorização profissional, ao cuidado prestado ao indivíduo de forma integral e humanizada. Portanto, tem-se como benefício uma formação voltada para a valorização do próximo e de si mesmo e, ainda, de profissionais técnicos em enfermagem responsáveis por realizarem um atendimento e cuidado de qualidade para o paciente e sociedade. 
Assim, essa pesquisa justifica-se pela proposta de repensar e refletir sobre o processo de formação de professores e estudantes do Curso Técnico de Enfermagem, com o objetivo de contribuir para formar profissionais para lidar com os problemas e dificuldades inerentes ao exercício da enfermagem, o sentido de trabalho em equipe, do diálogo, da comunicação e da reflexão.

Acreditamos que os princípios, estratégias e diretrizes da humanização podem colaborar para a formação inicial e continuada, para modificar o ambiente de trabalho, as relações humanas e o fortalecimento do serviço de saúde.

\section{Objetivos}

Compreender os significados de humanização na saúde atribuídos pelos docentes e por egressos do Curso Técnico em Enfermagem da ESTES/UFU.

Identificar e analisar a abordagem de humanização na saúde no PPP do Curso Técnico em Enfermagem da ESTES/UFU.

\section{Metodologia}

A pesquisa situa-se no campo da abordagem qualitativa da pesquisa em educação. Segundo Minayo (2002, p. 21) a pesquisa qualitativa "[...] trabalha com o universo de significados, motivos, aspirações, crenças valores e atitudes, o que corresponde a um espaço mais profundo das relações, dos processos e dos fenômenos". Trata-se de um estudo de caso sobre a humanização na saúde no Curso Técnico em Enfermagem da ESTES/UFU, observando os significados atribuídos pelos docentes e por egressos, bem como a abordagem no Projeto Político Pedagógico vigente em 2019, do referido curso.

O levantamento das referências bibliográficas referente à temática foi feito nas bases de dados das produções científicas brasileiras: Scientific Electronic Library Online (SIELO) e Biblioteca Virtual em Saúde (BVS) e Catálogo de Teses e Dissertações da CAPES. Na busca dos resultados foram utilizadas as palavras-chaves: humanização, saúde, enfermagem, ESTES, ensino. Além do uso dos descritores, os seguintes critérios foram empregados para a seleção do material: artigos científicos em português, publicados em periódicos nacionais, disponíveis na íntegra, online, dissertações e teses que abordem os descritores.

O Curso Técnico em Enfermagem da Escola Técnica de Saúde da UFU foi o local de escolha dessa pesquisa pela relevância social para cidade e região e por ser o ambiente de trabalho da pesquisadora. Os sujeitos participantes da pesquisa foram os docentes que atuaram no Curso Técnico em 
algum momento entre os anos de 2007 a 2017 e egressos que formaram em cada um dos anos do período citado.

Como critério de inclusão, os docentes deveriam fazer parte do quadro efetivo do Curso Técnico Enfermagem da ESTES/UFU, em qualquer período compreendido entre 2007 a 2017. Foram excluídos da pesquisa os docentes que não atuaram no Curso Técnico em Enfermagem no período determinado, professores substitutos, aposentados e a pesquisadora. O instrumento utilizado para coleta de informações foi um questionário semiestruturado, específico para os docentes e para os egressos contemplando questões abertas sobre a humanização na saúde no Curso Técnico em Enfermagem da ESTES/UFU.

Os participantes foram contatados pessoalmente, por ligação telefônica ou Whatsapp e convidados para participarem da pesquisa. Após o aceite dos participantes, foi agendado local, data e horário para aplicação dos questionários. Em 2019, havia 12 docentes efetivos na ESTES, dos quais 10 corresponderam ao critério de inclusão e aceitaram responder o questionário. Referente aos egressos foi realizado um sorteio com os nomes dos ex-alunos, formados entre 2007 e 2017, que constavam nos diários do Curso Técnico em Enfermagem. Foi impressa as listas dos egressos e colocado os nomes em caixas numeradas com ano de formação dos ex-alunos. De cada caixa foram sorteados 2 nomes de egressos, contemplando 20 nomes.

Foi entregue a ambos participantes, docentes e egressos, o questionário e o Termo de Consentimento Livre e Esclarecido e realizada uma explicação sobre o sigilo das informações. Para resguardar a identidade dos colaboradores, os docentes foram identificados pelas letras $\mathrm{D}$, acompanhada por números arábicos, de 1 até 10, (exemplo: D1) e os egressos foram identificados pela letra E por números arábicos, de 1 até 20 (exemplo: E1). Após a coleta dos dados, foi feita a leitura das respostas dos questionários. Foram analisados os significados, práticas e importância da humanização na saúde descritos pelos participantes. Dessa leitura e análise, verificamos que surgiram palavras repetidas e frases com sentidos similares descritos pelos sujeitos da pesquisa, em seguida identificamos e organizamos os temas comuns encontrados, originando quatro categorias referentes à Humanização na concepção de docentes e egressos: Atitudes Humanas, Empatia, Acolhimento, Valorização dos pacientes. Além dos questionários, foi analisada a abordagem da humanização na saúde no Projeto Político Pedagógico do Curso Técnico em Enfermagem, classificada como Humanização no Projeto Político Pedagógico. 


\section{Resultados - significados sobre humanização atribuídos por docentes e egressos}

\section{Atitudes Humanas}

A humanização pode ser entendida como questões subjetivas, vinculadas a valores qualitativos (CHERNICHARO; SILVA; FERREIRA, 2014), ações e sentimentos voltados para o bem do próximo. Verificamos que várias respostas dos questionários, abordaram a humanização em seu conceito subjetivo. Os participantes enfatizaram os aspectos intrínsecos dos seres humanos, as atitudes naturais que devem ser dispensadas aos pacientes durante a assistência, que deve ser feita de maneira humana e digna. Os docentes foram identificados com a letra "D", seguido da numeração; os Egressos com a letra "E", seguido da numeração.

\footnotetext{
Tratar o paciente com respeito, atenção, identificando suas necessidades, suas particularidades (E16).

Um atendimento digno, de qualidade e equidade, onde os usuários possam ter seus direitos respeitados (D2).

É ter a percepção e sensibilidade de um cuidado voltado não só para o corpo físico, mas também para o psíquico, com calor humano, com respeito e dando dignidade ao próximo (E 10).
}

Esse entendimento da humanização abrangendo características que visam fazer e querer bem ao próximo corroboram com diversos autores, como Rios (2009), Lazzari, Jacobs e Jung (2012), Sirino (2014) e Rocha e Cavalho (2007). Segundo Rios (2009, p. 254), o termo humanização “[...] em seu uso histórico o consagra como aquele que rememora movimentos de recuperação de valores humanos". Sirino (2014) demonstrou em sua pesquisa sobre a humanização no ensino de Graduação em Medicina, que uma das formas que os alunos entenderam a humanização foi como uma característica pessoal, aspectos que qualificam o atendimento, primando pela dignidade humana. Rocha e Carvalho (2007) levantaram o conhecimento de alunos de Graduação em Enfermagem sobre humanização da assistência, e eles referiram humanização como uma forma de tratar os clientes com respeito, tratando-os como seres humanos.

Compreendemos que esse conceito de humanização relacionado aos aspectos de bondade, cuidado amoroso e respeito ao ser humano, que os participantes descreveram, pode depender da vontade do profissional em exercer ou não ações humanizadoras, conforme Freire (1969, p. 3) relata: “[...] ambas, humanização e desumanização, são possibilidades históricas do homem como um ser incompleto e consciente de sua incompleticidade". Nesse 
contexto, a humanização poderia ser negada ao paciente e tornar o cuidado desumanizado. A PNH afirma que a humanização não deve ser vista como atitudes humanitárias, mas sim como uma política (BRASIL, 2004). Entendemos que docentes e egressos podem compreender a humanização além dos aspectos subjetivos e construir e desempenhar a humanização na assistência e gestão à saúde conforme as estratégias e metodologias da PNH.

\section{Empatia}

A empatia é a capacidade de reconhecer a complexidade pelo que o outro passa e entendê-lo. "É acolher as angústias do ser humano diante da fragilidade de corpo, mente e espírito [...] ser sensível à situação do outro" (PESSINI; BETARCHINO, 2006, p. 4). Identificamos que a empatia foi a palavra mais mencionada nos relatos dos egressos. Os docentes também citaram a empatia como significado de humanização.

Colocar-se no lugar do paciente, saber entender e compreender o que se passa com ele, cuidar da melhor forma, respeitando suas queixas e opiniões (E 6).

Sempre me coloco no lugar do paciente, então procuro atendê-lo como eu gostaria que fizessem comigo (E 16).

Para os investigados a empatia significa colocar-se no lugar do outro, compreendê-lo, ser solidário ao seu momento e tratá-lo como gostaríamos de ser tratados. No estudo de Silva, Chernicharo e Ferreira (2011, p. 383), os acadêmicos de enfermagem investigados “[...] defenderam que, ao nos colocarmos no lugar do outro, despertamos também nossos sentimentos, e assim temos condições de avaliar e acolher como gostaríamos de ser tratados naquele instante". De acordo com as repostas dos egressos e docentes, a empatia é uma ação que deve ser realizada para uma assistência humanizada. Concordamos que praticando a empatia, o profissional é capaz de compreender a situação que os pacientes vivenciam durante a internação e toda sua complexidade como ser humano, assim respeitar suas ideologias e escolhas, proporcionando uma comunicação efetiva, assegurando um atendimento humanizado.

\section{Acolhimento}

Nessa categoria, apenas os egressos citaram o acolhimento como forma de humanização. Descreveram como uma atitude ou atendimento acolhedor, que busca sanar as dúvidas e angústias do paciente e promover seu conforto, segurança e bem estar: 
[...] acolhimento do cliente [...], visando o melhor conforto, segurança, privacidade, compreensão e amor de forma individualizada (E 19).

Atendimento ao usuário de forma acolhedora, explicativa, onde serão sanadas suas dúvidas e ansiedades, buscando sempre o seu bem estar (E 17).

Para os participantes do estudo de Spinelli (2014), o acolhimento deve ser feito com atenção, buscando confortar o paciente. Silva, Chernicharo e Ferreira (2011), descreveram que os docentes de enfermagem expressam que estratégias de acolhimento fazem parte da humanização. De acordo com Brasil (2015) o acolhimento deve ser feito na assistência ao paciente, é um momento de realizar uma escuta qualificada.

Conforme documento da PNH, o acolhimento abrange a perspectiva ética, estética e política:

[...] ética no que se refere ao compromisso com o reconhecimento do outro, na atitude de acolhê-lo em suas diferenças, suas dores, suas alegrias, seus modos de viver, sentir e estar na vida; estética porque traz para as relações e os encontros do dia-a-dia a invenção de estratégias que contribuem para a dignificação da vida e do viver e, assim, para a construção de nossa própria humanidade; política porque implica o compromisso coletivo de envolver-se neste "estar com", potencializando protagonismos e vida nos diferentes encontros (BRASIL, 2010, p. 6).

O acolhimento é uma das diretrizes da $\mathrm{PNH}$, todavia, deve-se ressaltar que ele não foi citado pelos docentes, apenas pelos egressos. Os egressos, mesmo descrevendo o acolhimento como significado ou prática da humanização, necessitam de um embasamento teórico sobre essa diretriz. O docente é o profissional responsável por ensinar e construir com os alunos, os saberes e práticas necessárias para a formação desses futuros profissionais.

\section{Valorização do paciente}

Os docentes e egressos relataram que a assistência humanizada deve atender as necessidades do paciente, deve ser realizado um cuidado que valorize todas as dimensões do ser humano e que os profissionais devem promover o protagonismo dos sujeitos.

Humanização é colocar o paciente como o sujeito do cuidado, sempre em primeiro lugar, respeitando suas necessidades individuais, crenças, esclarecendo as dúvidas e oferecendo cuidado integral (D 9). 
Essencial, fundamental na prática e cuidado de enfermagem; um cuidado com o indivíduo na sua essência física, mental, social, vendo todas suas vertentes (D 4).

Compreendo a humanização na saúde com o enfoque do cuidado/ assistência ao paciente/ usuário, este como protagonista de sua saúde e processos de cuidado [...] (D 8).

De acordo com Rocha e Carvalho (2007), na opinião dos estudantes de graduação em enfermagem, os principais conceitos de humanização destacados na pesquisa foram: tratar o paciente com respeito, atender as necessidades do cliente, tratar as pessoas como seres humanos e proporcionar cuidado holístico. Esse cuidado, citado nas respostas apresentadas, está de acordo com o que PNH propôs, a humanização "[...] deve compreender a proposta de abordagem integral do ser humano, superando a fragmentação do olhar e intervenções sobre os sujeitos, que devem ser vistos em suas inseparáveis dimensões biopsicossociais" (BRASIL, 2008, p. 63).

O protagonismo dos sujeitos é um dos princípios prezados pela $\mathrm{PNH}$. Segundo a PNH o protagonismo "[...] é a ideia de que a ação, a interlocução e a atitude dos sujeitos ocupam lugar central nos acontecimentos" (BRASIL, 2008, p. 65). Todo o processo de assistência à saúde deve ser voltado para contemplar o paciente em todas suas vertentes e necessidades, proporcionando um acolhimento eficaz e um cuidado pautado na humanização. A PNH ainda descreve que o protagonismo, "[...] no processo de produção da saúde, diz respeito ao papel de sujeitos autônomos e corresponsáveis no processo de produção de sua própria saúde" (BRASIL, 2008, p. 65).

Portanto, os relatos apresentaram um conceito de humanização como política, concebida como valorização do paciente, onde o profissional deve atender todas as necessidades dos pacientes, observando os aspectos biopsicossociais e deve estimular o protagonismo dos pacientes nas ações de saúde, em conformidade com o documento da PNH.

\section{Humanização no PPC do Curso Técnico em Enfermagem}

$\mathrm{Na}$ área da saúde, desde a criação da Política Nacional de Humanização, busca-se desenvolver uma cultura de humanização nos profissionais da saúde e "[...] que deve estender-se, também à formação educacional dos profissionais de saúde” (BRASIL, 2001, p. 5). Nessa perspectiva, avaliamos a abordagem da humanização no PPP do Curso Técnico em Enfermagem da ESTES/UFU.

$\mathrm{Na}$ análise do documento, abrangendo a justificativa e objetivos, perfil profissional de conclusão e organização curricular, verificamos que a palavra humanização e PNH não foram descritas, porém foram mencionados termos 
que fazem referência sobre a humanização. Identificamos os seguintes termos correlatos presentes no PPP: cidadania e direitos do cidadão, ética, solidariedade, conduta humana, assistência integral à saúde e visão holística, autonomia, relações humanas, comunicação interpessoal, interagir com a equipe.

Em estudos correlatos Lima et al (2011), Almeida e Chaves (2009), Carvalho et al (2016), os autores verificaram a inserção da humanização nos currículos de Graduação em Enfermagem e identificaram a presença de termos que fazem referência à humanização na saúde. Corsino e Sei (2019) realizaram essa mesma abordagem nos cursos de saúde: Medicina, Educação Física, Enfermagem, Farmácia, Odontologia, Fisioterapia, Psicologia, Nutrição, Fonoaudiologia e Terapia Ocupacional, constataram que os cursos que abordaram o tema humanização, foram Enfermagem, Farmácia, Fisioterapia, Psicologia e Terapia Ocupacional. Gonzaga (2009) e Abreu (2016) analisaram o PPP dos Cursos Técnicos de Enfermagem da Escola Técnica de Saúde do SUS (ETSUS) de Palmas e do Instituto Federal do Norte de Minas Gerais (IFNMG) campus Januária, respectivamente e constataram que houve a abordagem de termos sobre humanização nos cursos avaliados.

O currículo do Curso Técnico em Enfermagem deve ser organizado de forma a abordar o homem em sua totalidade, associar conhecimentos teóricos com as práticas e contextos de saúde, possibilitar novas abordagens que contemplem a humanização como política na assistência e gestão à saúde. Verificamos que o PPP da ESTES/UFU apresenta termos pertinentes à humanização, porém, como falar de humanização sem mencioná-la? Há uma lacuna que deve ser preenchida. Nesse contexto, defendemos inserir o conteúdo e a prática da humanização na saúde como política $(\mathrm{PNH})$, durante todo o curso e não apenas a intenção de abordá-lo, fazendo de forma a articular o saber, com o fazer e com o ser, proporcionando ao aluno uma formação humanística.

\section{Considerações finais}

A humanização na saúde é discutida no Brasil, desde a década de 1950 e assumia um significado subjetivo, uma concepção que remetia a natureza humana, de preocupar-se com o bem do paciente, possibilitar um cuidado personalizado, com atenção, preocupação, acolhimento. Todavia, era necessário investir em medidas mais incisivas para modificar o cenário precário da saúde pública. Nesse contexto, o Ministério da Saúde criou, em 2003, uma política específica de humanização dos serviços de saúde, a Política Nacional de Humanização, que propõe uma gama de ações e estratégias para fortalecer e qualificar o SUS. A PNH deve ser disseminada, construída e exercida tanto nos 
ambientes de saúde como nas instituições de formação dos profissionais, para alcançar efetivamente a qualidade da assistência e gestão da saúde.

Buscamos compreender os significados de humanização na saúde atribuídos pelos docentes e egressos do Curso Técnico em Enfermagem da ESTES/UFU e como o Projeto Político Pedagógico do curso aborda o tema humanização. De acordo com os resultados obtidos os docentes e egressos descreveram a humanização vinculada às atitudes e ações de querer bem ao paciente. Relataram que buscam prover um cuidado de qualidade, com amor, respeito, atenção, sensibilidade, empatia, entre outras características de valores humanos. Reiteraram que a humanização é feita acolhendo e valorizando o paciente, proporcionando um cuidado holístico e estimulando seu protagonismo, conforme perspectiva da PNH. Constatamos que os participantes enfatizaram a humanização como aspectos subjetivos, relacionados à natureza humana. A humanização como política foi pouco abordada.

Ressaltamos que, para que a humanização seja realizada de maneira efetiva, o docente deve abordar seu conceito político, uma vez que a $\mathrm{PNH}$ promove a humanização na saúde de forma efetiva e sistematizada, incluindo, valorizando e beneficiando todos os sujeitos envolvidos no processo de saúde.

Outro aspecto abordado na pesquisa foi a presença do tema humanização no PPP do curso, que resultou na ausência da palavra humanização ou PNH, porém, foram encontrados termos relacionados ao que a humanização estabelece como: cidadania e direitos do cidadão, ética, solidariedade, conduta humana, assistência integral à saúde e visão holística, autonomia, relações humanas, comunicação interpessoal, interagir com a equipe. Esses termos possibilitam o entendimento que a humanização, em alguns aspectos, é abordada nas disciplinas do curso, mas, cabe ressaltar que os termos não contemplam a humanização na saúde na sua amplitude e a palavra humanização, que é a base desse estudo não foi mencionada, possibilitando a compreensão de que o tema é abordado de maneira superficial ou fragmentada.

Entendemos que a humanização em seu significado político, conforme foi estabelecida pela $\mathrm{PNH}$, deve ser inserida no currículo do Curso Técnico em Enfermagem da ESTES/UFU de maneira clara, detalhada, abrangendo todo o documento da $\mathrm{PNH}$ e que sua abordagem se dê de forma a perpassar toda a formação do aluno, que seja considerado um tema transversal. O currículo do curso deve ser estruturado de forma que os conhecimentos sejam integrados entre as disciplinas, a teoria e prática da humanização constituam-se de maneira articulada e relacionada ao contexto social e de saúde do país e o aluno desenvolva habilidades técnicas e emocionais necessárias para uma assistência à saúde de qualidade. 
Cabe reforçar, que os docentes são agentes realizadores dessa mudança, é preciso que eles avaliem as melhores estratégias e metodologias de ensino e aprendizagem sobre a humanização na saúde. Eles devem estimular sua discussão e prática, porque a humanização quando vivenciada e aprendida é incorporada na forma de ser e agir do estudante. Portanto, os docentes do Curso Técnico em Enfermagem devem trabalhar a humanização em todos os seus aspectos, até aqui discutidos, cooperando para a edificação de um aluno autêntico, problematizador, participativo, responsável, atuante, que realize uma assistência humanizada, saiba construir relações e transformar realidades.

\section{Referências}

ALMEIDA, D. V.; CHAVES, E. C. O ensino da humanização nos currículos de graduação em enfermagem. Revista Einstein, São Paulo, v. 7, n. 3, p. 271 278, 2009. Disponível em: http://apps.einstein.br/revista/arquivos/PDF/1233-Einstein\%20v7n3p2718_port.pdf. Acesso em: 10 nov. 2019.

\section{ABREU, K. J. V. D. Avaliação do curso técnico em enfermagem sob o} enfoque da humanização. 2016. Dissertação (Mestrado Profissional em Ensino em Saúde) - Programa de Pós-graduação em Ensino em Saúde, Universidade Federal dos Vales do Jequitinhonha e Mucuri, Diamantina, 2016. Disponível em: http://acervo.ufvjm.edu.br/jspui/handle/1/1051. Acesso em: 13 ago. 2019.

BRASIL. [Constituição (1988)]. Constituição da República Federativa do Brasil de 1988. Brasília, DF: Presidência da República, [2016]. Disponível em: http://www.planalto.gov.br/ccivil_03/constituicao/constituicao.htm. Acesso em: 25 nov. 2019.

BRASIL. Lei $\mathbf{n}^{\mathbf{0}} \mathbf{8 . 0 8 0}$, de 19 de setembro de 1990. Dispõe sobre as condições para a promoção, proteção e recuperação da saúde, a organização e o funcionamento dos serviços correspondentes e dá outras providências. Brasília, DF: Presidência da República, [1990]. Disponível em: http://www.planalto.gov.br/ccivil_03/leis/18080.htm. Acesso em: 16 jun. 2019.

BRASIL. Ministério da Saúde. Secretaria Executiva. SUS princípios e conquistas. Brasília, DF: Ministério da Saúde, dez. 2000. Disponível em: http://www.saude.gov.br/sistema-unico-de-saude/principios-do-sus. Acesso em: 10 jul. 2018. 
BRASIL. Ministério da Saúde. Secretaria de Assistência à Saúde. Programa

Nacional de Humanização da Assistência Hospitalar. Brasília, DF:

Ministério da Saúde, dez. 2001. Disponível em:

https://bvsms.saude.gov.br/bvs/publicacoes/pnhah01.pdf. Acesso em: 10 jul. 2018.

BRASIL. Ministério da Saúde. Secretaria Executiva. Núcleo Técnico da Política Nacional de Humanização. Humaniza SUS-Política Nacional de

Humanização: a humanização como eixo norteadoras das práticas de atenção e gestão em todas as instâncias do SUS. Brasília, DF: Ministério da Saúde, 2004. Disponível em:

http://bvsms.saude.gov.br/bvs/publicacoes/humanizasus_2004.pdf. Acesso em: 10 jul. 2018.

BRASIL. Ministério da Saúde. Núcleo Técnico da Política Nacional de Humanização. Humaniza SUS: Documento base para gestores e trabalhadores do SUS. 4. ed. Brasília, DF: Ministério da Saúde, 2008. Disponível em: http://www.planalto.gov.br/ccivil_03/_Ato2007-2010/2008/Lei/L11892.htm. Acesso em: 14 jan. 2019.

BRASIL. Ministério da Saúde. Acolhimento nas práticas de produção de saúde. 2. ed. Brasília, DF: Ministério da Saúde, 2010. Disponível em: http://bvsms.saude.gov.br/bvs/publicacoes/acolhimento_praticas_producao_ saude.pdf. Acesso em:15 jul. 2019.

BRASIL. Ministério da Saúde. Núcleo Técnico da Política Nacional de Humanização. Humaniza SUS: Política Nacional de Humanização (PNH). Brasília, DF: Ministério da Saúde, 2015. Disponível em: http://bvsms.saude.gov.br/bvs/folder/politica_nacional_humanizacao_pnh_1 ed.pdf. Acesso em: 10 set. 2019.

CARVALHO, N. M. et al. O ensino da humanização no curso de bacharel em enfermagem numa universidade pública. Revista de Enfermagem da UFPE, Recife, v. 10, n. 12, p. 4554-462, dez. 2016. Acesso em: 20 jun. 2019.

CHERNICHARO, I. M.; SILVA, F. D.; FERREIRA, M. A. Caracterização do termo humanização na assistência por profissionais de enfermagem. Escola Anna Nery, Rio de Janeiro, v. 18, n. 1, p. 156-162, mar. 2014. Disponível em: http://www.scielo.br/scielo.php?script=sci_arttext\&pid=S141481452014000100156\&lng=en\&nrm=iso. Acesso em: 02 ago. 2019.

COFEN. Conselho Federal de Enfermagem. Resolução Cofen no 564/2017. Aprova o novo Código de Ética. Brasília, DF, 6 nov. 2017. Disponível em: http://www.cofen.gov.br/resolucao-cofen-no-5642017_59145.html. Acesso em: 18 set. 2019. 
COFEN. Conselho Federal de Enfermagem. Enfermagem em Números. Brasília, DF, 2019. Disponível em: http://www.cofen.gov.br/enfermagem-emnumeros. Acesso em: 18 set. 2019.

CORSINO, D. L. M.; SEI, M. B. A Humanização nas grades curriculares de cursos da saúde de universidades públicas paranaenses. Revista de Psicologia e Saúde, Campo Grande, v. 11, n. 1, p. 43-52, abr. 2019. Disponível em: http://pepsic.bvsalud.org/scielo.php?script=sci_arttext\&pid=S2177093X2019000100003\&lng=pt\&nrm=iso. Acesso em: 13 fev. 2020

FREIRE, P. Papel da Educação na Humanização. Revista Paz e Terra, São Paulo, n. 9, p. 123-132, out. 1969. Disponível em:

http://acervo.paulofreire.org:8080/xmlui/handle/7891/1127.Acesso em: 03 out. 2018.

GONZAGA, V. F. A humanização como tema transversal no Curso Técnico de Enfermagem da ETSUS/TO. 2009. Dissertação (Mestrado Profissional em Saúde e Gestão do Trabalho) - Programa de Pós-Graduação em Saúde e Gestão do Trabalho Universidade do Vale do Itajaí, Itajaí, 2009. Disponível em:

http://www.dominiopublico.gov.br/pesquisa/DetalheObraForm.do? select_action=\&co_obra=181393. Acesso em: 13 abr. 2019.

LAZZARI, D. D.; JACOBS, L. G.; JUNG, W. Humanização da assistência na enfermagem a partir da formação acadêmica. Revista de Enfermagem da UFSM, [S.l.], v. 2, n. 1, p. 116-124, abr. 2012. Disponível em: https://periodicos.ufsm.br/reufsm/article/view/3705. Acesso em: 13 dez. 2020 .

LIMA, J. O.R. et al. A formação ético-humanista do enfermeiro: um olhar para os projetos pedagógicos dos cursos de graduação em enfermagem de Goiânia, Brasil. Interface, Botucatu, v. 15, n. 39, p. 1111-1126, dez. 2011. Disponível em: http://www.scielo.br/scielo.php?pid=S141432832011000400012\&script=sci_abstract\&tlng=pt. Acesso em: 13 nov. 2019.

MINAYO, M. C. S. Ciência, técnica e arte: o desafio da pesquisa social. In: MINAYO, M. C. S. (org.). Pesquisa Social: teoria método e criatividade. 21. ed. Petrópolis: Vozes, 2002. p. 9-30.

PASCHE, D. F.; PASSOS, E. A importância da humanização a partir do Sistema Único de Saúde. Revista Saúde Pública de Santa Catarina, Florianópolis, v. 1, n. 1, jan./jun. 2008. Disponível em: http:/ livroaberto.ibict.br/bitstream/1/546/1/A\%20import $\% C 3 \% A 2$ ncia \%20da\%20humaniza\%C3\%A7\%C3\%A3o.pdf.Acesso em: 18 jul. 2019. 
PESSINI, L; BERTACHINI. Humanização e Cuidados Paliativos. 3. ed. São Paulo: Edições Loyola, 2006.

RIOS, I. C. Humanização: a essência da ação técnica e ética nas práticas de saúde. Revista Brasileira de Educação Médica, Rio de Janeiro, v. 33, n. 2, p. 253-261, jun. 2009. Disponível em: http://www.scielo.br/scielo.php? script=sci_arttext\&pid=S0100-55022009000200013. Acesso em: 13 dez. 2019 .

ROCHA, D.; CARVALHO, R. Humanização da assistência: o que pensam os estudantes de enfermagem. Revista Einstein, São Paulo, v. 5, n. 4, p. 315-320, 2007. Disponível em: http://apps.einstein.br/revista/arquivos/PDF/600Einstein_OnLineTraduzida_Vol.5(4)_Miolo_P\%C3\%A1g.315\%20a \%20320.pdf. Acesso em: 13 set. 2019.

SANTOS, E. F. et al. Legislação em Enfermagem: atos normativos do exercício e do ensino de enfermagem. São Paulo: Atheneu, 1997.

SILVA, F. D.; CHERNICHARO, I. M.; FERREIRA, M. A. A humanização na ótica de professores e acadêmicos: estado da arte do conhecimento da enfermagem. Ciência, Cuidado e Saúde, Maringá, v. 10, n. 2, p. 381-388, abr./jun. 2011. Disponível em:

http://periodicos.uem.br/ojs/index.php/CiencCuidSaude/article/view/ 10189/pdf.Acesso em: 10 nov. 2018.

SIRINO, C. B. A humanização no ensino de graduação em medicina: construções sobre o olhar dos estudantes. 2014. Dissertação (Mestrado em Ciências) - Faculdade de Medicina, Universidade de São Paulo, São Paulo, 2014. Disponível em: https://teses.usp.br/teses/disponiveis/5/5137/tde-14112014143601/pt-br.php. Acesso em: 03 out. 2019.

SPINELLI, C. R. B. Concepções sobre o ensino da humanização em cursos técnicos de enfermagem de Porto Alegre. 2014. Dissertação (Mestrado em Biociências e Reabilitação) - Pós Graduação em Biociências e Reabilitação, Centro Universitário Metodista, Porto Alegre, 2014. Disponível em: https://catalogodeteses.capes.gov.br/catalogo-teses/\#!/. Acesso em: 03 jun. 2019. 